\title{
Neck Pain and Acute Dysphagia
}

\author{
João Simões ${ }^{1,2}$ (1) José Romão ${ }^{1,2} \cdot$ Anita Cunha $^{1,2} \cdot$ Sofia Paiva ${ }^{1,2} \cdot$ António Miguéis $^{1,2}$
}

Received: 17 August 2016/Accepted: 22 November 2016/Published online: 30 November 2016

(C) Springer Science+Business Media New York 2016

\begin{abstract}
The acute tendinitis of the longus colli muscle is an unusual diagnosis in the cases of acute dysphagia with cervical pain. Is a self-limiting condition caused by abnormal calcium hydroxyapatite deposition in the prevertebral space and can cause pharyngeal swelling with impaired swallow. It is absolutely critical to make the differential diagnosis with deep cervical infections in order to avoid invasive treatments.
\end{abstract}

Keywords Deglutition - Deglutition disorders - Dysphagia · Pain · Tendinitis

\section{Case}

A 48-year-old man was admitted to our ENT department with severe dysphagia and odynophagia with $24 \mathrm{~h}$ of evolution. He had a sharp neck pain exacerbated with cervical extension. A sub-febrile temperature $\left(37.5^{\circ}-38.0^{\circ}\right)$

João Simões

jofsim@gmail.com

José Romão

zeromao@gmail.com

Anita Cunha

anita.cunha.85@gmail.com

Sofia Paiva

sofpaiva@gmail.com

António Miguéis

amigueis@fmed.uc.pt

1 Department of Otorhinolaryngology, Coimbra Hospital and University Center, Coimbra, Portugal

2 Faculty of Medicine, University of Coimbra, Coimbra, Portugal was registered during the initial crisis and no other symptoms were present. The patient denied history of neck trauma, foreign body ingestion, and upper respiratory tract infection.

At the physical examination, he was trying to avoid cervical movements, and the observation of the pharynx revealed a protuberance and marked swelling in the posterior pharyngeal wall extending from the nasopharynx to the hypopharynx. The cervical palpation increased the pain, but no mass or swelling was detected.

Besides recent history of tooth cavities treatment, the patient was otherwise healthy. The blood analysis showed an increase in C-reactive protein $(9.86 \mathrm{mg} / \mathrm{dL})$ and leukocytosis of $12.5 \times 10^{9} / \mathrm{L}$. The diagnostic hypothesis of pharyngeal abscess was placed and imaging study was carried out with computer tomography (CT) of the neck. At this moment, the patient was submitted to intravenous antibiotics ( $2 \mathrm{~g}$ of ceftriaxone) and corticosteroids (125 mg of methylprednisolone) were also provided.

The CT revealed a liquid retropharyngeal collection from $\mathrm{C} 2$ to $\mathrm{C} 5$ without organized limits (Figs. 1, 2, 3). In the same study, calcifications at the levels of $\mathrm{C} 1$ and $\mathrm{C} 2$ prevertebral spaces were visible. Large or swollen lymph nodes were not detected.

\section{What is the Likely Diagnosis?}

Considering the CT study, the diagnosis of acute tendinitis of the longus colli muscle was established and the patient continued with intravenous methylprednisolone. Neck immobilization and soft diet were also applied.

During the first $24 \mathrm{~h}$, a notable improvement was observed and a complete normal physical examination was 


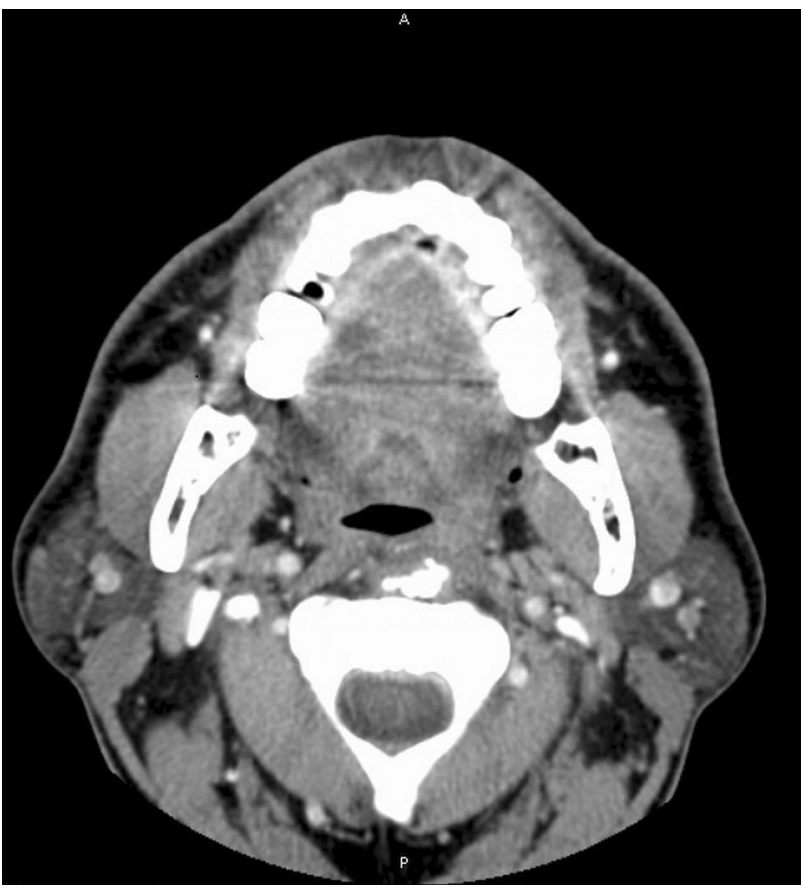

Fig. 1 Computer tomography study of the neck. Axial view showing calcium deposits in the thickened prevertebral soft tissues

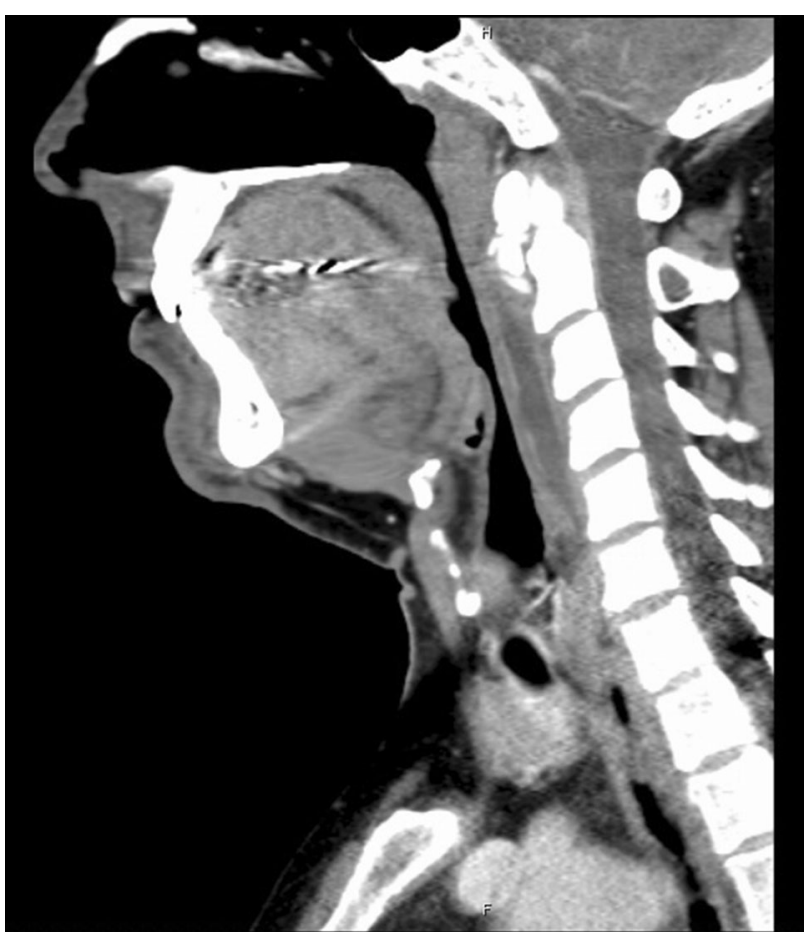

Fig. 2 Computer tomography study of the neck. Sagittal view with volume increase of the prevertebral soft tissue and hypodensity of the retropharyngeal space. Calcium deposits are also seen

achieved after $72 \mathrm{~h}$. After 3 days of hospitalization, the patient was discharged with short course of oral non-steroidal anti-inflammatory drug.

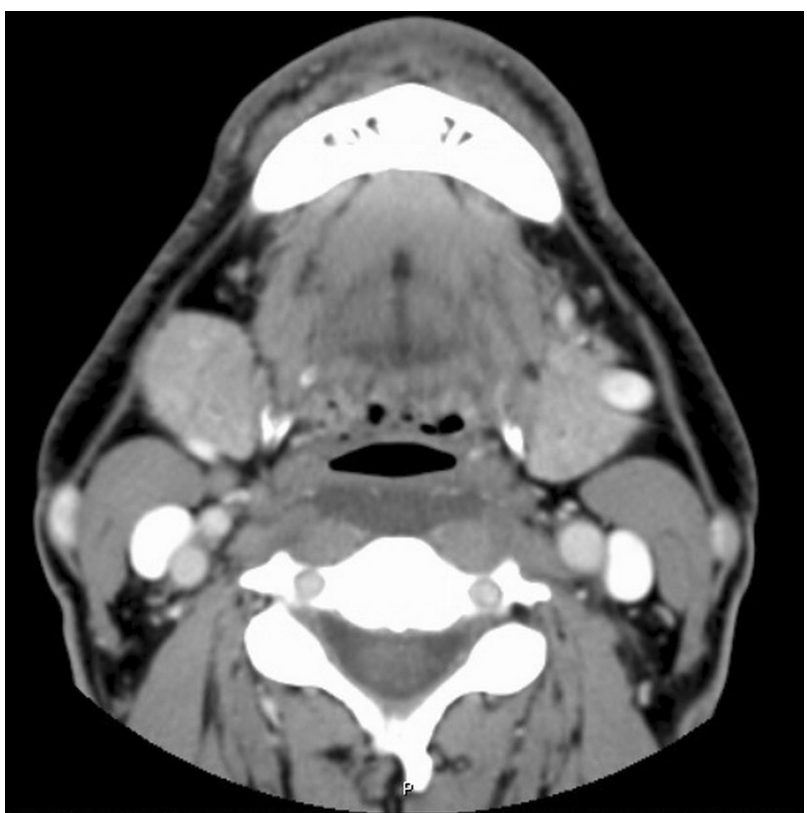

Fig. 3 Computer tomography study of the neck. Axial view with swelling of the posterior pharyngeal wall narrowing the upper airway

This report is clinically relevant considering the unusual presentation of the longus colli tendinitis with severe dysphagia and the important differential diagnosis with deep cervical infection and infectious spondylitis. In our case, this is especially relevant considering the history of tooth disease.

\section{Discussion}

The tendinitis of the longus colli muscle, which is also known as prevertebral calcific tendinitis or retropharyngeal calcific tendinitis, is a rare and frequently underdiagnosed pathology, caused by the deposition of calcium hydroxyapatite crystal in the longus colli muscle tendons [1,2]. These deposits result in local tissue inflammation and perilesional edema, which can cause a protuberance in the posterior pharyngeal wall impairing the deglutition [3].

The longus colli muscles are flexor muscles in the prevertebral space and their extension from the upper mediastinum to the atlas's anterior tubercle leads to a clinical presentation similar to cervical abscess [4].

In the work of Silva et al. the analysis of 134 contrastenhanced neck CT studies retrieved nine cases of prevertebral calcific tendinitis [1]. In all cases, the presentation was posterior cervical pain, which was exacerbated by movements and occurred without fever [3]. Eight out of nine cases presented without odynophagia contrasting with our case, which had odynophagia and dysphagia. All the 
cases also showed a slight increase in the C-reactive protein [1].

Imaging techniques are critical for accurate diagnosis. The differential diagnosis with retropharyngeal abscess is based on the distribution of hypodense thickening and absence of parietal enhancement.

The retropharyngeal calcific tendinitis has been reported as self-limiting and with excellent prognostic. Its clinical management includes symptomatic management with nonsteroidal anti-inflammatory medications and muscle relaxants which generally induces a favorable response within $48-72 \mathrm{~h}$, as we observed with our patient. Furthermore, corticosteroids and opioids are also a treatment option. We also consider the short period of soft diet as a good non-pharmacologic adjunct therapy that contributes to reduce the pain.

Although self-limiting and with excellent prognosis, the tendinitis of the longus colli muscle presents with acute cervical pain similar to life-threatening cervical infections that require surgical treatment. Thus, clinicians should be familiar with this disease in order to avoid aggressive and invasive therapies.

\section{Compliance with Ethical Standards}

Conflict of interest The authors have no conflict of interest to declare.

\section{References}

1. Silva CF, Soffia PS, Pruzzo E. Acute prevertebral calcific tendinitis: a source of non-surgical acute cervical pain. Acta Radiol. 2014;55(1):91-4.

2. Offiah CE, Hall E. Acute calcific tendinitis of the longus colli muscle: spectrum of CT appearances and anatomical correlation. Br J Radiol. 2009;82:e117-21.

3. Razon RV, Nasir A, Wu GS, et al. Retropharyngeal calcific tendonitis: report of two cases. J Am Board Fam Med. 2009;22:84-8.

4. De Maeseneer M, Vreugde S, Laureys S, et al. Calcific tendinitis of the longus colli muscle. Head Neck. 1997;19:545-8.

João Simões MD

José Romão MD

Anita Cunha MD

Sofia Paiva MD

António Miguéis $\mathrm{MD}, \mathrm{PhD}$ 